\title{
Tesis de Economía septiembre 1992 - septiembre 1993
}

\author{
Departamento de Economía \\ Universidad Centroamericana José Simeón Cañas
}

- Análisis de la Nueva Ley Orgánica del Banco Central de Reserva de El Salvador, y sus implicaciones en el Sistema Financiero Nacional. Presentada por: Flor Argentina Castañeda de Salas.

- Las Políticas de Precios de los Granos Básicos en El Salvador: una Evaluación Crítica.

Presentada por: Sonia Elizabeth Chong Díaz.

- La Aplicación del Programa de Ajuste Estructural en Centroamérica y su Incidencia en el Proceso de Integración Económica 1987-1991.

Presentada por: Ramona Mercedes Galán, Mario Ernesto Morán Zamora y Juan Antonio Cortez Iraheta.

- Vetanjas y Desventajas de la Adhesión de El Salvador al Gatt. Presentada por: Carmen Elena Castillo Escobar, Alfonso Adalberto Ayala Dimas.

- Proyecto Calle Real: ¿un Proyecto de Nueva Economía Popular? Presentada por: Helga Elisa Cuéllar Marchelli, Rhina Maria Ferrer Morán.

- Limitantes y Potencialidades de los Pequeños Productores Agropecuarios para su Conversión a la Nueva Economía Popular. Presentada por: Abraham Heriberto Mena Vásquez, Maria de Jesús Vega Alas. 
- Plan de Reconstrucción Nacional su Impacto en la Economía Nacional 1992-1993.

Presentada por: Alda Celia Argüello, Ricardo Miguel Granillo Funes.

- La Nueva Economía Popular en el Area Metropolitana de San Salvador, Limitantes y Potencialidades.

Presentada por: Raúl Ernesto Artiga Colato, Virginia Guadalupe Hernández Ramirez, Julio César Mendieta Carías.

- La Ley Salvdaoreña de Protección al Consumidor: Análisis y Recomendación para su Perfeccionamiento.

Presentada por: Sandra Patricia Medrano de Peña, Marta Eugenia Moisa de Orozco. 